\title{
Proibição da maconha no Brasil e suas raízes históricas escravocratas
}

\author{
André Barros ${ }^{1}$ e Marta Peres ${ }^{2}$
}

\section{Resumo:}

Este texto discute a proibição da maconha no Brasil, iniciando por uma visão histórica do uso do cânhamo desde o Paleolítico até os primeiros livros impressos e as Grandes Navegações. Em seguida, são abordadas as leis penais brasileiras e suas transformações ao longo das condições da Colônia, Reino Unido, Império e República, enfatizando a marca racista que séculos de regime escravocrata deixam no imaginário social. Após a abolição da escravatura e a proclamação da República, concomitantemente à imigração europeia e ao desejo de 'embranquecer' a sociedade brasileira, o racismo passou a se sustentar sobre as bases pseudocientíficas do pensamento Lombrosiano, que chegaram através de autores Positivistas. Finalmente, são reportados os fatos mais marcantes do proibicionismo em relação às drogas e as mudanças no campo legal ao longo dos séculos XX e XXI, relacionando-os ao relevante papel das Marchas da Maconha no Brasil e no mundo.

\section{Palavras-chave}

Maconha; poder punitivo; História do Brasil; racismo; direito penal

\section{Marijuana Prohibition in Brazil and Slavery Historical Roots}

\begin{abstract}
:
The subject of this paper is marijuana prohibition in Brazil. It begins with an overall view of the use of hemp from the Paleolithic to the early printed books and Great Navigations seafaring. Then, we discuss Brazilian penal law and its changes during Colony, Portuguese United Kingdom, Empire and Republic, pointing out the racist mark on Brazilian social imaginary after centuries of slavery practices. With the abolition of slavery and the proclamation of Republic, while European immigration was stimulated as a way of "whitening" Brazilian society, racism was supported by the pseudoscientific ideas of Lombroso, brought by Positivist thinkers. Finally, recent facts in this field are reported including penal law changes during the $X X$ and XXI centuries pointing out the relevance of National and Global Marijuana March Movement in this process.

\footnotetext{
1 Advogado criminalista, Mestre em Ciências Penais (UCAM).

2 Professora Adjunta da Escola de Educação Física e Desportos, UFRJ. Doutora em Sociologia (UnB).
} 


\section{Keywords}

Marijuana; punitive power; History of Brazil; racism; criminal law

\section{No passado era legal}

A política criminalizadora de condutas relacionadas à produção, à distribuição e ao consumo de determinadas substâncias psicoativas e matérias primas para sua produção, ocultando a identidade essencial em todas as substâncias psicoativas e a artificialidade da distinção entre drogas lícitas e ilícitas, é, hoje, a mais organizada, mais sistemática, mais estruturada, mais ampla e mais danosa forma de manifestação do proibicionismo a nível mundial. (Karam, 2009:1).

Ao apontar a artificialidade inerente à distinção entre as chamadas drogas lícitas e ilícitas, a juíza Maria Lucia Karam demonstra o caráter de construção social do proibicionismo nesse campo, tema desenvolvido ao longo deste texto, em especial, sob uma perspectiva histórica. De fato, embora tenha sido tornada uma droga ilícita no século passado, anteriormente, a maconha era não somente legalizada, como consistia num relevante insumo econômico na Europa, utilizado desde os tempos do paleolítico. Escrita com as mesmas sete letras, a palavra maconha é um anagrama de cânhamo, matéria-prima de grande importância no Renascimento. Gutenberg utilizou papel de cânhamo para produzir as 135 primeiras Bíblias impressas do mundo, localizando-se um desses exemplares no acervo da Biblioteca Nacional, na Cinelândia, Rio de Janeiro.

Na Renascença, a maconha era um dos principais produtos agrícolas da Europa. Prova de sua grande influência na mudança de mentalidades é que, além das páginas de papel de cânhamo dos primeiros livros impressos, artistas pintavam em telas feitas com suas fibras. Tanto que a palavra Canvas, usada em várias línguas para designar "tela", é uma corruptela holandesa do latim 'cannabis': daí dizer-se 'oil on canvas' (óleo sobre tela)'. 
Desde a antiguidade, gregos e os romanos usaram velas e cordas de cânhamo nos navios. No século XV, cultivado nas regiões de Bordéus e da Bretanha, na França, em Portugal e na África, o cânhamo era destinado à confecção de cordas, cabos, velas e material de vedação dos barcos, que inundavam com frequência em longas navegações. O produto obtido de suas fibras, dotado de rigidez e elasticidade, proporcionava às caravelas uma enorme velocidade. Incluindo velame, cordas e outros materiais, havia 80 toneladas de cânhamo no barco comandado por Cristóvão Colombo, em 1496 (Robinson, 1999). O cultivo de cânhamo em terras lusas tornou-se massivo à época das Grandes Descobertas, pois fornecia o material das embarcações portuguesas. Decreto do rei $D$. João $V$, de 1656, comprova que o incentivo à produção de maconha era uma política de Estado.

Tendo chegado graças às velas de cânhamo de suas embarcações, a história oficial diz que foi Pedro Alvares Cabral que descobriu o Brasil. Como já viviam milhões de nativos aqui, chamados pelos portugueses de índios, pois imaginavam estar chegando às Índias, ninguém descobriu nada! Ou então, podemos dizer que a maconha descobriu o Brasil.

\section{Poder Punitivo no Brasil}

A fim de enfocar a questão do poder punitivo, saltamos alguns séculos, para o momento em que a Coroa Portuguesa fugiu das tropas de Napoleão, em novembro de 1807. Ao chegarem ao Brasil, os cerca de 15 mil portugueses assustaram-se com a ideia de viver numa cidade cuja maioria da população era formada de escravos.

Além do âmbito da segurança pessoal e coletiva, o intendente de polícia, figura importada da metrópole, era responsável pelas obras públicas e pela garantia de abastecimento de água e iluminação da cidade, atividades economicamente relacionadas. Na qualidade de 
supervisor de obras, o intendente "tinha nos presos um fluxo contínuo de mão-de-obra, que ele podia transferir da cadeia ou pelourinho para as obras da estrada" (Idem:53).

Com a função de manter a tranquilidade da ordem pública e o patrulhamento da cidade, em 1809, foi criada a Guarda Real de Polícia. À medida que seus truculentos membros passavam paulatinamente a substituir os antigos capitães-do-mato, sua atuação relacionava-se à "polícia de costumes", ou seja, repressão de festas com cachaça, música afro-brasileira e, evidentemente, maconha. Ataques a quilombos situados nos morros eram uma das principais atividades repressivas. Consta que o policial Miguel Nunes Vidigal, célebre pelo terror que espalhava entre os "vadios e ociosos", na maioria, escravos que iam aos "batuques", prendeu certa vez mais de 200 pessoas, dentre homens, mulheres e crianças, num quilombo do Morro de Santa Teresa (Idem Ibidem:46-7) ${ }^{3}$.

Tendo surgido oficialmente em 1808, no contexto da vinda da família real, a polícia brasileira foi constituída sem qualquer limite legal, já que uma lei penal propriamente dita somente entrou em vigor em 1830. Nesta época, conviviam elementos ideológicos contraditórios, à medida que o Brasil, desde o século anterior, passava a representar um papel importantíssimo para a economia portuguesa. Sob um aparente liberalismo da metrópole, aumentava a opressão sobre a colônia. De fato, "uma série de reformas inspiradas no despotismo esclarecido tornou o controle português mais penetrante, eficiente e opressivo para o nativismo brasileiro emergente" (Holloway, 1997:44).

Enquanto na metrópole, onde fora criada a Intendência, vigorava o despotismo esclarecido e já se podia identificar alguma

3 "Esses ataques brutais eram chamados de 'ceias de camarão', alusão à necessidade de descascar o crustáceo para se chegar à sua carne cor-de-rosa. Em vez do sabre militar comum, o equipamento normal de Vidigal e seus granadeiros era um chicote de haste longa e pesada, com tiras de couro crú em uma das extremidades, o qual podia ser usado como cacete ou chibata" (Idem Ibidem: 49). 
atenção aos Direitos Individuais, o mesmo não ocorreu aqui: ao contrário, na colônia, as Reformas Pombalinas traduziam-se num aumento da fiscalização e da repressão. Até a partida de Dom João VI em 1821, as leis criminais que vigoravam no Brasil eram as do Livro $V$ das Ordenações Filipinas. No entanto, as leis eram editadas pela polícia sob um regime totalmente absolutista. Para se ter uma ideia da brutalidade das normas no Brasil, é emblemática a comparação com um relatório do estado de Virgínia, Estados Unidos, em 1825, onde o maior castigo a um escravo consistia em 39 açoites pelo furto de um par de botas:

As penas eram brutalmente severas, por menores que fossem as infrações, até mesmo pelo padrão das décadas seguintes e em comparação com a escravidão urbana em outros lugares. Contrastando com a norma de aplicar 100 a 300 açoites por pequenos crimes no Rio de Janeiro, não raro seguidos de vários meses de trabalho forçado em grilhões, vem do sul dos Estados Unidos o seguinte relatório de crimes e castigos de escravos em Richmond, Virgínia, em 1825: "Furto de três dólares, 20 açoites; três cobertores, 15, quatro dólares, 25; vestido de algodão, 15 açoites; par de botas, 39; leito de pernas, 10 ". Se a escravidão no Brasil patrimonial e católico era mais branda do que nos Estados Unidos capitalista e protestante, tal diferença dificilmente se estenderia aos castigos impostos aos escravos urbanos por pequenos crimes. (op. cit.:55)

Observa-se que, antes do Código Criminal do Império (1830), eram aplicados entre 100 a 300 açoites para pequenos crimes, pelo Intendente da Polícia e pela Guarda Real. Além disso, no Brasil, os castigos chegavam a assumir o risco de matar o escravo.

Encerradas as guerras napoleônicas, em 1820, intimado a retornar a Lisboa, o rei deixou como regente seu primeiro filho, Pedro de Bragança e Bourbon. Logo em seguida, Dom Pedro I decretou que "ninguém poderia ser preso senão em flagrante ou por ordem judicial", que "as acusações deveriam ser propostas até 48 horas após a prisão" e que "ninguém seria encarcerado senão por decisão do Tribunal", o que foi considerado um grande avanço. Além disso, 
proibiu o uso de grilhões, correntes e tortura como punição, embora escravos não gozassem de tais direitos. A crise entre os partidos brasileiro e português, junto à influência de ideias liberais, desembocou no "Grito do Ipiranga", proclamado por Dom Pedro em 7 de setembro de 1822. Em 1824, D. Pedro I outorgava o primeira Constituição do Brasil, curiosamente denominada "liberal", porém, outorgada. Nela, já estavam insculpidos os Direitos Humanos de Primeira Geração ${ }^{4}$, mas é interessante observar que tenha convivido com o Código Criminal de 1830: legislações com princípios antagônicos. Deste, pode ser citada a crueldade das penas de galés, em que os réus eram sujeitados a andar de calcete no pé e corrente de ferro. O artigo 46 determinava o trabalho forçado dentro das prisões. Deste modo, os direitos individuais garantidos pela Constituição de 1824, como o princípio da reserva legal, eram apenas fachada, à medida que se mantinham antigas formas de punir. Em especial, no que diz respeito às duas condições do escravo, simultaneamente considerado coisa e réu.

Deste modo, identificamos que as raízes da criminalização da maconha no Brasil estão indiscutivelmente ligadas à diáspora africana. A violência até hoje nutrida contra tal hábito dos negros é compreendida se considerarmos que, no Brasil, a escravidão foi tão brutal que, com toda sua crueldade, ainda assim, o Código Criminal de 1830, primeira lei penal brasileira, foi considerada um avanço, ao ter estabelecido que o escravo que cometesse um pequeno delito deveria receber, por dia, no máximo, 50 chicotadas, já que antes, como citado acima, eram entre 200 a 400 :

Art. 60 Se o réo fôr escravo, e incorrer em pena que não seja a capital ou de galés, será condemnado na de açoutes, e, depois de os soffrer, será entregue a seu senhor, que se obrigará trazêl-o

4 Os Direitos Humanos são classificados segundo a primeira geração, baseada na ideia de cidadão, segunda, nos aspecto moral e social, terceira, na soberania nacional, e quarta, ligada à ecologia, minorias, respeito às diferenças (Bobbio, 1992:62) 
com um ferro pelo tempo e maneira que o juiz o designar. $\mathrm{O}$ número de açoutes será fixado na sentença; e o escravo não poderá levar por dia mais de concoenta.

No mesmo ano em que este código entrou em vigor, o Brasil foi o primeiro país do mundo a editar uma lei contra a maconha: em 4 de outubro de 1830, a Câmara Municipal do Rio de Janeiro penalizava o 'pito de pango ', denominação da maconha, no $\S 70$ da postura que regulamentava a venda de gêneros e remédios pelos boticários:

É proibida a venda e o uso do pito do pango, bem como a conservação dele em casas públicas. Os contraventores serão multados, a saber: o vendedor em 20\$000, e os escravos e mais pessoas, que dele usarem, em três dias de cadeia. (Mott in Henman e Pessoa Jr., 1986).

\section{Fim da escravidão e entrada do pensamento lombrosiano}

Embora tivessem apoiado o movimento da Independência, por se preocuparem com a manutenção da estabilidade e da "paz social", as elites brasileiras não desejavam uma ruptura com os moldes da sociedade colonial. Sem dúvida, temiam a ameaça representada pelo grande contingente populacional de negros. Em defesa de uma suposta 'ordem pública', historicamente, as elites colocavam-se como "vítimas" da violência urbana. Embates nas ruas da capital culminaram com a criação da Guarda Municipal e Nacional, em 1831. Bastava possuir alguma renda e não ser um ex-escravo para poder se alistar em tais instituições paramilitares. Com o fim da figura do capitão-do-mato, seus representantes passaram a integrar as novas instituições oficiais ou a fazer parte da estrutura informal de repressão enquanto "jagunços".

Chamamos atenção aqui para os aspectos ideológicos que embasam a elaboração de leis. Segundo Michel Foucault, com a passagem dos regimes monárquicos para os republicanos, o centro das preocupações do poder punitivo deixou de focalizar na figura do 
rei e voltou-se para a proteção do "corpo social". Buscando a assepsia $^{5}$ da sociedade, modificavam-se as respectivas formas de segregar os excluídos, pela adoção de novas medidas de controle social. Princípios básicos da República, essas "receitas terapêuticas" para a sociedade incluíam a eliminação dos doentes, o controle dos contagiosos, a exclusão dos delinquentes (Foucault, 1979:37).

No Brasil, a implantação dessas medidas fundamentou-se no pensamento positivista, que aqui chegou junto a valores que desembocaram na Abolição da Escravatura e na Proclamação da República. Tanto é que se faz presente no lema da bandeira: "Ordem e Progresso". Enfraquecia-se a oligarquia escravocrata, enquanto aliavam-se militares com ideais positivistas e setores economicamente emergentes ainda excluídos de participação política no Brasil Imperial da segunda metade do século XIX.

A primeira Constituição republicana teve como modelo a Constituição dos Estados Unidos da América, introduzindo o presidencialismo e o federalismo, consagrando o regime representativo de eleições diretas, embora excluísse analfabetos, mulheres, soldados, integrantes de ordens religiosas e menores. Fortemente relacionado ao pensamento de Lombroso (1835-1909) ${ }^{6}$, o positivismo influenciou o Direito Penal. Imediatamente após a Abolição da Escravatura $(1888)^{7}$, essas ideias caíram como uma luva no Brasil. Com suas bases supostamente científicas, o etnocentrismo se vestia com uma nova forma de dominação, mais sutil, porém

5 Assepsia: Conjunto das medidas adotadas para evitar a chegada de germes a local que não os contenha (Ferreira, 1986:184). Limpeza.

6 Criminologista italiano cujas teorias buscavam relacionar traços físicos das pessoas a seus aspectos mentais e de comportamento. Inspirado em estudos genéticos e evolutivos no final do século XIX, afirmava que os criminosos possuíam evidências físicas de um "atavismo" (reaparição de características de ascendentes distantes) hereditário, reminiscente de estágios mais primitivos da evolução humana, anomalias em termos de formas do crânio e mandíbula, face e outras partes do corpo. Posteriormente, estas associações foram consideradas inconsistentes ou inexistentes.

7 Foi grande a pressão da Inglaterra, desejosa de conquistar novos mercados consumidores, cujos tratados com Portugal, em 1810, 1815 e 1817, previam breve fim para a escravidão no Brasil. Decisão unilateral inglesa, o Aberdeen Act (1845) permitia que navios ingleses atacassem navios negreiros até mesmo em portos brasileiros. 
muito violenta. Se os castigos aplicados no tempo da escravidão não seriam mais oficialmente admitidos, no alvorecer do século $X X$, cresceu a preocupação com as leis e sua cientificidade.

Assim, desde a Proclamação da República (1889) ao início da "Era Vargas" (1930), a criminologia sustentava origens etiológicas para o crime. Em outras palavras, referia-se à existência de razões biológicas, atávicas e até climáticas (calor, no caso) para que determinados tipos de pessoas não respeitassem a ordem. Características tais como o tamanho da mandíbula forneciam dados à psicopatologia criminal. Apesar de inconsistentes, suas teorias influenciaram criminologistas, juristas e médicos, brasileiros e europeus. O positivismo apresenta diagnósticos e soluções para casos isolados, culpabilizando o indivíduo e não o sistema social, gerando um pensamento racista e sensacionalista que muito agrada às classes privilegiadas. Ao explicar a origem dos revolucionários, bandidos, alcoólatras, desempregados, mendigos, prostitutas e maconheiros por meio de características atávicas, o discurso lombrosiano visava a assepsia da sociedade que deveria ser protegida desses (maus) "elementos".

Além disso, naquele momento, o país tinha que se adaptar, ainda que na condição de periferia, ao Sistema Capitalista Industrial. O discurso liberal e racional veio junto com novas relações de produção e com a busca de mercados, pois escravos não poderiam consumir como os assalariados. Contudo, prova de que as condições escravocratas permaneceram, é que, até mais tarde, no Código Penal de 1940, ainda era necessário criminalizar a escravidão. De um lado, parecia que uma moderna República não admitia conviver com tal "selvageria" e brutalidade. Entretanto, esta realidade não se extinguiu totalmente com a República, como ainda se faz presente até hoje.

Apesar da pressão inglesa, também contribuiu para o fim da escravidão a ameaça da sociedade pela continuidade da vinda de 
escravos e pelas rebeliões da senzala. O medo da africanização por parte das elites consistia num risco para a segurança pública e afastava o Brasil das "rotas da civilização" ${ }^{\prime 8}$. O desequilíbrio entre a população brasileira livre e cativa era enorme, já que, entre 1500 e 1822, enquanto vieram cerca de um milhão de portugueses, vieram três milhões de africanos. Apesar da historiografia oficial ter procurado camuflar a maioria de africanos como "povoadores forçados" do território brasileiro, o fato é que os líderes e as elites percebiam esse predomínio e alertavam para o risco das rebeliões escravas.

Medidas abolicionistas começaram a ser adotadas pelo governo brasileiro por volta de 1850, quando subia o preço dos escravos, de modo que tornava-se menos oneroso importar mão-de-obra excedente da Europa. Parte do dinheiro dos fazendeiros empregado anteriormente no tráfico negreiro passou a ser investido na imigração9. O medo da sociedade brasileira desses "inimigos domésticos" somado à necessidade de trabalhadores para a agricultura, estimulou a vinda dos imigrantes europeus (Del Priore e Venâncio, 2001:225-9). No final do século XIX, o desemprego e as más-condições de vida no campo consistiam em problemas seríssimos na Europa, de modo que governo brasileiro e fazendeiros paulistas aproveitaram para promover uma política de estímulo à imigração, no intuito de "embranquecer" o Brasil. Defensores da imigração européia achavam que, assim, "aprimorariam" a sociedade.

8 Em 1835, a "Revolta dos Malês", em Salvador, Bahia, aterrorizou os brancos, ao descobrirem planos, escritos em árabe, que previam a morte de todos os brancos imediatamente após a conquista do poder pelos escravos.

9 Os avanços do transporte internacional, o medo das revoltas dos escravos e a carência de mão-deobra para a lavoura de café motivaram a imigração, principalmente de italianos, simultaneamente à expansão da lavoura cafeeira, na virada dos séculos XIX para o XX. Pode-se argumentar que não havia carência de mão-de-obra, já que havia milhares de escravos libertados sem trabalho. No entanto, com o trauma, assim que libertados, aliviados da brutal repressão, em busca de liberdade, os negros abandonavam as fazendas e procuravam terrenos baldios em que pudessem plantar milho e mandioca para comer (Campos,2005:41-2). Simultaneamente, buscava-se construir uma 'nação homogeneizada', sobre padrões culturais europeus, o negro ex-escravo não fazia parte deste projeto, mas queria viver. Não houve qualquer política humanitária, nem para os imigrantes europeus, tampouco para os afrodescendentes. 
O desejo de liberdade dos ex-escravos era considerado "falta de vontade de trabalhar": chamados de vagabundos, por meio da convivência como os estrangeiros europeus, os negros aprenderiam o espírito do homem livre e trabalhador.

Recordamos que a política criminal implantada pelo Estado até meados do século XIX era de extermínio dos indígenas e escravidão para os negros. Transformações de um país até então eminentemente rural, o processo de 'embranquecimento' e o início da industrialização trouxeram necessidades diferentes ao novo sistema, que precisava mascarar a política punitiva e de fortes raízes escravocratas com novas roupagens.

\section{Proibição da maconha no Brasil}

Conforme mencionado, a psiquiatria lombrosiana chegou ao Brasil em meados do século XIX. Ao defender que determinadas raças carregavam características naturais dos criminosos, seu discurso pseudo científico criminalizou os negros, sua religião, sua cultura e, obviamente, o hábito de fumar maconha. Prova de que esse hábito foi trazido da África pelos escravos é que uma das mais conhecidas denominações da maconha era "fumo de Angola". Deste modo, seu consumo era considerado um impulsionador da prática de condutas penais e seus consumidores, tidos como criminosos de antemão. Com a Abolição da Escravatura, esse pensamento viria auxiliar a controlar e reprimir a liberdade, de maneira que antigos escravos e seus descendentes foram criminalizados. Observem que a escravidão foi abolida em 1888, a República foi proclamada em 1889 e a sua Constituição entrou em vigor em 1891. Um ano antes mesmo de ser promulgada sua lei maior, a República tratou de instaurar dois instrumentos de controle dos negros em 1890: o Código Penal e a "Seção de Entorpecentes Tóxicos e Mistificação", a fim de combater 
cultos de origem africana e ao uso da cannabis, utilizada em rituais do Candomblé, considerado "baixo espiritismo".

Alguns anos depois, o psiquiatra Rodrigues Dória ${ }^{10}$ (1857-1958) teve grande influência na criminalização da maconha, chegando a associá-la a uma espécie de vingança de negros "selvagens" contra brancos "civilizados" que os haviam escravizado. Vejamos um fragmento de seu texto etnocêntrico, discriminando a cultura, a religião e o maravilhoso diálogo rimado da diversidade cultural brasileira dos negros, nativos e pobres:

...é possível que um individuo já propenso ao crime, pelo efeito exercido pela droga, privado de inibições e de controle normal, com o juízo deformado, leve a prática seus projetos criminosos . (...) Entre nós a planta é usada, como fumo ou em infusão, e entra na composição de certas beberragens, empregadas pelos "feiticeiros", em geral pretos africanos ou velhos caboclos. Nos "candomblés" - festas religiosas dos africanos, ou dos pretos crioulos, deles descendentes, e que Ihes herdaram os costumes e a fé - é empregada para produzir alucinações e excitar os movimentos nas danças selvagens dessas reuniões barulhentas. Em Pernanmbuco a herva é fumada nos "atimbós" - lugares onde se fazem os feitiços, e são frequentados pelos que vão aí procurar a sorte e a feliciadade. Em Alagoas, nos sambas e batuques, que são danças aprendidas dos pretos africanos, usam a planta, e também entre os que "porfiam na colcheia", o que entre o povo rústico consistem em diálogo rimado e cantado em que cada réplica, quase sempre em quadras, começa pela deixa ou pelas últimas palavras de contendor (Henman e Pessoa Jr, 1986).

Como podemos ver, psiquiatras brasileiros elaboraram uma série de teses criminalizando negros, nativos, mulheres, capoeiristas, sambistas, maconheiros, prostitutas, macumbeiros, cachaceiros, explorando certo tipo de discurso que estigmatizava todos que não fossem supostamente brancos "puros", próximo daquele que viria a originar também ideias fascista e nazista da superioridade de raças.

10 Professor de Medicina Pública de Direito da Bahia, presidente da Sociedade de Medicina Legal, expresidente do Estado de Sergipe, 
Já nos anos 1940, embora Filinto Muller, influente chefe da polícia política de Getúlio Vargas, declarasse que a Umbanda não fazia mal a ninguém, invadia e quebrava todos os terreiros que insistiam no uso da maconha. Como havia o desejo da Umbanda, que estava se estruturando, ser reconhecida como religião, subtraiu-se o uso da maconha de suas práticas para obter esse reconhecimento. Identifica-se aí um traço de embranquecimento, ainda que forçado, da Umbanda. Ao mesmo tempo em que eram descriminalizadas as religiões de origem africana, a capoeira e o samba, a maconha foi criminalizada pelo artigo 281 do Código Penal de 1940.

\section{Proibição da Maconha no Brasil e no Mundo}

(...) vale acrescentar (à conceituação de proibicionismo) a mais bem humorada tradução dada pelo Professor Charles Whitebread à ideia de proibição, definindo-a como a utilização da lei penal para criminalizar condutas que grande parte de nós parece querer praticar... (Karam, 2009 ;2)

A primeira ação internacional no sentido de promover uma proibição coordenada à produção, distribuição e ao consumo de determinadas substâncias psicoativas e suas matérias primas foi sistematizada na Convenção Internacional sobre o Ópio, organizada pela Liga das Nações, em Haia, no ano de 1912 (Karam, 2009 : 3). A referida convenção recomendava aos Estados signatários que examinassem a possibilidade de criminalização da posse de ópio, morfina, cocaína e seus derivados. Inspirada nela, em 1921, entrou em vigor, no Brasil, o Decreto número 4294, que punia tão somente o comércio de "substância de qualidade entorpecente".

Na II Conferência Internacional do Ópio, em Genebra, 1925, vale destacar a afirmação de Dr. Pernambuco, para delegações de 45 outros países: "a maconha é mais perigosa que o ópio". Cabe destacar que, apesar da cocaína e da morfina já haverem sido 
incluídas desde a anterior, ambas as convenções tinham como objetivo o combate ao ópio. Considerando que esta erva não constava da recomendação de 1912, esse médico, indiscutivelmente, influenciou a criminalização da maconha em todo o mundo. Em outras palavras, foi baseada nas ideias racistas e escravocratas presentes no discurso de um psiquiatra brasileiro, que a criminalização da maconha viria a ser internacionacionalizada.

Em 1931, foi realizada a Convenção de Genebra, que regulamentaria as duas convenções internacionais anteriores. Nela, a criminalização não chegou a ser imposta, mas já avançava no sentido de uma ideologia proibicionista.

Em 1932, entrou em vigor, no Brasil, o decreto 2930 que passava a penalizar também o usuário, porém, diferenciando-o do traficante. Merece destaque o Decreto-Lei 891/38 que estabeleceu a toxicomania como doença compulsória, tratando de internação civil e interdição dos toxicômanos. Em 1940, entrou em vigor um novo Código Penal, que apenava a conduta de traficar, em seu famoso artigo 281, inclusive mencionado em canção do saudoso Bezerra da Silva.

Três convenções da ONU dirigidas contra as drogas tornadas ilícitas expressaram-se acerca da matéria: a Convenção Única sobre entorpecentes (1961), o Convênio sobre substâncias psicotrópicas (1971) e a Convenção das Nações Unidas contra o tráfico ilícito de entorpecentes e substâncias psicotrópicas (Viena, 1988).

Em 1968, em plena ditadura militar, por meio do Decreto-Lei 385 e alteração do artigo 281 do Código Penal, o usuário foi equiparado ao traficante, sendo-Ihes atribuídas penas idênticas. Em 29/10/1971, foi editada a lei 5726, que mantinha esta equiparação e trazia medidas ainda mais profundamente repressivas, tais como o oferecimento de denúncia mesmo sem qualquer substância, ou seja, sem existência de prova material. Esta situação de exceção era 
análoga ao que o regime militar também fazia por meio da Lei de Segurança Nacional, pela qual qualquer policial, sem ordem judicial, podia prender uma pessoa e deixá-la incomunicável com sua família ou advogado por trinta dias, renováveis através apenas de uma comunicação ao juiz, por mais trinta.

Em 1976, entrou em vigor a histórica lei 6368, que distinguia o traficante - tipificado no artigo 12 - do usuário, tipificado no artigo 16 - tendo vigorado em parte até 2002, quando FHC sancionou a lei $10409 / 2002$, a qual sofreu tantos vetos que se tornou absolutamente sem sentido. Embora tenha se reunido recentemente às trincheiras dos ativistas pró-legalização, durante seu mandato na Presidência do Brasil, Fernando Henrique Cardoso nada mudou sobre a legislação de drogas, à medida que afirmou-se da Lei 10.409/2002 estar apenas trocando 'seis por meia dúzia'. Seu sucessor, Lula, embora não tenha se posicionado publicamente sobre o tema, em meio ao processo de sua reeleição, em agosto de 2006, sancionou a Lei 11343, que acabou com a pena de prisão para os usuários de substâncias ilegais e para quem plantar pequena quantidade de maconha para uso próprio. Na realidade, os artigos 12 e 16 da Lei 6368/76 vigoraram até 2006 quando foram finalmente revogados pelo Lei 11343/2006. Pois FHC fez tantos vetos a sua própria Lei 10409/2002, que tais artigos criminalizadores continuaram em vigor.

\section{Hoje}

Em 2009, foi encaminhada uma representação à ProcuradoriaGeral da República, noticiando decisões judiciais que proibiam as Marchas da Maconha em cidades brasileiras. Impulsionada pela mesma, a Procuradora Debora Macedo Duprat de Britto Pereira propôs a Arguição de Descumprimento de Preceito Fundamental no 187, que o Supremo Tribunal Federal julgou procedente, por 
unanimidade, no dia 15 de junho de 2011, baseado no relatório e voto memorável do Ministro Celso de Mello.

Até então, passaram-se anos de luta, tendo mais de 100 pessoas sido presas dentre os que convocavam e participavam das Marchas. Após a histórica Marcha de São Paulo, o Supremo julgou procedente a ação, de modo que o protesto de ativistas na rua acarretou o reconhecimento da legalidade democrática do movimento e a ilegalidade das recentes medidas judiciais repressivas.

Em maio de 2012, por decisão da maioria do seu Plenário, o Supremo Tribunal Federal, no Habeas Corpus no 104339, declarou incidentalmente inconstitucional parte do artigo 44 da Lei 11343/2006, que proibia a concessão de liberdade provisória em caso de tráfico de entorpecentes. A regra é o direito de responder a uma acusação criminal em liberdade. Para decretar a provisória prisão preventiva, o Juiz precisa apresentar fatos e elementos que demonstrem a presença de seus requisitos, que são: de ordem pública, quando há provas de que em liberdade o indiciado poderá praticar outros crimes; para garantia da instrução criminal, quando o acusado estiver coagindo alguma testemunha; ou para assegurar a aplicação da lei penal, pois o denunciado pode fugir da cidade. Tratam-se de alguns exemplos para se tirar, excepcionalmente, a liberdade de alguém. O STF assegurou, assim, a necessidade da análise dos requisitos da prisão preventiva para a medida excepcional. O Juiz não pode mais decretar a prisão de uma pessoa argumentando a vedação da lei à liberdade provisória, pois a Suprema Corte declarou sua inconstitucionalidade.

Tal medida é importantíssima, pois bem mais da metade dos presos no Brasil - constituída de primários, de bons antecedentes, com residência fixa, desarmados no momento do crime, sem pertencer à qualquer organização criminosa, e, pior, sem obrigar ninguém a comprar dele a droga tornada ilícita - está na cadeia por 
tráfico. O senso comum leva a crer que os presos são poderosos traficantes, mas esses são franca minoria. Os verdadeiros traficantes são milionários e bilionários que agem no sistema bancário em aplicações financeiras, compras de imóveis, mas esses nunca serão presos, porque a cadeia serve, com raríssimas exceções, para punir e controlar os pobres. Mas não se deve pensar que não existe tipificação de crime para os financiadores. Apesar de não podermos dar a conhecimento um caso concreto, cabe destacar o artigo 36 da Lei $11343 / 2006$, que, por incrível que pareça, está em vigor:

"Art. 36. Financiar ou custear a prática de qualquer dos crimes previstos nos arts. 33, caput e $\S 1^{\circ}$, e 34 desta Lei:

Pena - reclusão, de 8 (oito) a 20 (vinte) anos, e pagamento de 1.500 (mil e quinhentos) a 4.000 (quatro mil) dias-multa."

A pena real para os verdadeiros traficantes e corruptos seria a perda dos bens, que está na Constituição, mas não está regulamentada em lei infraconstitucional, mesmo vigorando o inciso XLVI do seu artigo $5^{\circ}$ da Carta Política:

"Art. 50....

XLVI - a lei regulará a individualização da pena e adotará, entre outras, as seguintes:

a) privação ou restrição da liberdade;

b) perda de bens;

c) multa;

d) prestação social alternativa;

e) suspensão ou interdição de direitos;"

No final de 2011, o Supremo Tribunal Federal já havia decidido, através de seu Plenário Virtual, que um caso de porte de maconha na cadeia tinha repercussão geral. Isto significa que o STF pode decidir, nesse caso, que a criminalização do consumo de drogas tornadas ilícitas é inconstitucional, por diversos motivos: primeiro, porque fere o princípio da igualdade, ao criminalizar consumidores de drogas ilícitas, enquanto é descriminalizado o consumo de drogas lícitas; 
segundo, porque viola o princípio da lesividade, quando criminaliza uma conduta que não atinge terceira pessoa, mas apenas o próprio usuário, que atinge somente sua saúde e jamais a saúde pública; terceiro, pois a criminalização ataca a racionalidade do discurso iluminista do "Império da Lei", ao desrespeitar as garantias republicanas da intimidade e vida privada. Leis não podem violar essas garantias individuais, pois o Estado não pode intervir na escolha individual do que é consumido nem controlar o direito de cada um dispor de sua própria vida. A auto-lesão, assim como o suicídio, não é crime. De fato, ninguém pode ser processado por "tentativa de suicídio" e muito menos por suicídio!

Este ano foi apresentado ao Senado, por uma Comissão de Juristas, projeto do novo Código Penal, que exclui o crime para quem estiver portando quantidade equivalente a cinco dias de consumo. Além disso, um anteprojeto de lei, apresentado e divulgado na mídia pela OnG Viva Rio, propõe a descriminalização do porte de uma quantidade equivalente a dez dias de consumo.

Outro fato que vem sendo debatido é o Plano Nacional de Segurança Pública proposto pelo presidente Mujica do Uruguai, a fim de combater a violência e o consumo de crack. Neste projeto, o Estado venderia quarenta baseados - cigarros de maconha - a um usuário por mês.

Aqui, no Brasil, ao levarmos em consideração as mudanças nos níveis judicial e legal, é fundamental ressaltar que as Marchas da Maconha influenciaram estes avanços. A rua é um importantíssimo palco da política, garantido pelo artigo $5^{\circ}$, inciso XVI, da Constituição Federal/1988: "todos podem reunir-se pacificamente, sem armas, em locais abertos ao público, independentemente de autorização, desde que não frustrem outra reunião anteriormente convocada para 0 mesmo local, sendo apenas exigido prévio aviso à autoridade competente". Deste modo, adeptos e simpatizantes participam das 
Marchas da Maconha, mostrando sua força para legalizar a maconha no Brasil e no mundo.

Estamos caminhando para a legalização, mas a reação dos punitivos proibicionistas é notória. Delegados, Promotores e Juízes não aplicam a lei e condenam milhares de jovens consumidores como traficantes, numa espécie de vingança pelos avanços de dispositivos libertários, como o fim da pena de prisão para consumidores e plantadores de pequena quantidade previstos no artigo 28 da Lei 11343/2006. Um fato que exemplifica esta reação é que, mesmo garantida pelo Supremo Tribunal Federal, a Marcha da Maconha de 2012 foi brutalmente reprimida em Ipanema.

Em breve, provavelmente, a Suprema Corte julgará a inconstitucionalidade da criminalização do consumo e do porte para uso próprio, pois, por todas as razões apresentadas, trata-se de grave violação às garantias republicanas dos Direitos Humanos de Primeira Geração.

\section{Referências Bibliográficas}

Barros, André Magalhães. A acumulação do poder punitivo no Brasil. Dissertação de Mestrado em Direito (Ciências Penais). Orientadora: Vera Malaguti Batista. Universidade Cândido Mendes, 2006.

Bobbio, Norberto. A Era dos Direitos. Rio de Janeiro: Campus, 1992.

Foucault, Michel. Vigiar e Punir. Petrópolis: Vozes, 1986.

Henmam, Anthony. Pessoa Jr, Osvaldo. Diamba Sarabamba. Coletânea de textos brasileiros sobre a maconha. São Paulo: Ground, 1986.

Holloway, Thomas. Polícia no Rio de Janeiro. Repressão e Resistência numa cidade do século XIX. Rio de Janeiro: Fundação Getúlio Vargas, 1997. 
Peres

Karam, Maria Lúcia. Proibições, Riscos, Danos e Enganos: as Drogas Tornadas Ilícitas. Vol 3. Rio de Janeiro: Lumen Juris, 2009.

Robinson, Rowan. O Grande Livro da Cannabis. Guia completo de seu uso industrial, medicinal e ambiental. Rio de Janeiro: Jorge Zahar, 1999. 